JOEAI (Journal of Education and Instruction)

Volume 2, Nomor 1, Juni 2019

e-ISSN : 2614-8617

p-ISSN : 2620-7346

DOI : https://doi.org/10.31539/joeai.v2i1.758

IMARERE

\title{
PENGARUH PEMBERIAN REWARD TERHADAP MOTIVASI BELAJAR SISWA PADA MATA PELAJARAN PENDIDIKAN AGAMA ISLAM
}

\author{
Marliza Oktapiani ${ }^{1}$, Yu'la Rahmawati ${ }^{2}$, Ifham Choli $^{3}$ \\ Universitas Islam As-Syafi'iyah Bekasi ${ }^{1,2,3}$ \\ marlizaoktapiani.fai@uia.ac.id ${ }^{1}$
}

\begin{abstract}
ABSTRAK
Penelitian ini, bertujuan untuk mengetahui pengaruh pemberian reward terhadap motivasi belajar siswa pada mata pelajaran Pendidikan Agama Islam di SMP IT ArRudho Kota Jakarta Timur. Dalam penelitian ini, menggunakan metode field research, yaitu penelitian lapangan atau observasi dan pembagian instrument berupa angket yang akan dikumpulkan dan dijadikan sumber untuk menganalisis. Pengujian hipotesis menggunakan korelasi pearson product moment yaitu untuk mencari korelasi atau hubungan antara variabel X (Pemberian Reward) dengan variabel Y (Motivasi Belajar). Hasil penelitian ini menunjukan bahwa adanya pengaruh pemberian reward terhadap motivasi belajar siswa, hal ini terlihat dari dari nilai indeks korelasi (rhitung) yaitu $0,401 \geq$ ( $\mathrm{r}$ tabel) 0,254 artinya ada pengaruh yang cukup kuat dari pemberian reward terhadap motivasi belajar siswa. Maka dapat disimpulkan bahwa dengan adanya pemberian reward dapat meningkatkan motivasi belajar siswa. Sehingga pemberian reward dapat memacu siswa lebih giat dalam proses pembelajaran di sekolah.
\end{abstract}

Kata Kunci: Reward, Motivasi Belajar

\section{ABSTRACT}

This research aims to determine the effect of giving rewards on the student learning motivation in learning PAI at SMPIT Ar-Rudho Jakarta. The method used in this research is field research which is in the form of observation and distribution of questionnaires that will eventually be collected and used as the source for data analysis. The hypotheses were tested using Pearson product moment correlation to find a correlation between variable X (Giving Rewards) and variable Y (Learning Motivation). The findings of this research indicate that there is an effect of giving rewards on the student learning motivation. This can be seen from the correlation index value - (r observed) $0.401 \geq$ ( $r$ table) 0.254 - which means that there is a strong enough influence of giving rewards on the student learning motivation. It can be concluded that the provision of rewards can increase student motivation. So that giving rewards can encourage students to be more active in the learning process at school.

Keywords: Reward, Learning Motivation 


\section{PENDAHULUAN}

Pekembangan Ilmu Pengetahuan yang semakin modern terutama pada era globalisasi seperti sekarang ini menuntut kita untuk terus meningkatkan kualitas pendidikan. Sebab sumber daya manusia yang berkualitas merupakan prasyarat untuk mencapai tujuan pembangunan. Salah satu wahana untuk meningkatkan sumber daya manusia tersebut adalah pendidikan. Dalam Undang-Undang Republik Indonesia No. 20 Tahun 2003 tentang Sistem Pendidikan Nasional, bahwa: Pendidikan adalah usaha sadar dan terencana untuk mewujudkan suasana belajar dan proses pembelajaran agar peserta didik secara aktif mengembangkan potensi dirinya untuk memiliki kekuatan spiritual keagamaan, pengendalian diri, kepribadian, kecerdasan, akhlak mulia, serta ketrampilan yang dibutuhkan bagi dirinya, masyarakat dan bangsa. (Wahab, 2009)

Sedangkan menurut Wahab (2009) pendidikan adalah upaya sadar dan terencana yang dilakukan oleh keluarga, masyarakat, dan pemerintah melalui kegiatan bimbingan, pengajaran, dan atau latihan yang berlangsung disekolah maupun luar sekolah untuk mempersiapkan peserta didik agar dapat memainkan peranannya secara tepat dalam berbagai lingkungan hidup.

Rendahnya motivasi siswa dikelas bisa disebabkan oleh pribadi diri siswa sendiri dan metode mengajar yang digunakan guru terlalu monoton seperti metode ceramah yang sering digunakan guru dalam kegiatan belajarnya, sehingga kurang menarik bagi siswa. Seorang guru tidak hanya mampu menyampaikan pelajaran kepada siswa dengan baik saja namun juga harus mampu memotivasi siswa. Dalam proses pendidikan, motivasi itu sangat penting karena motivasi merupakan syarat mutlak untuk belajar. Di sekolah seringkali terdapat anak yang malas, tidak menyenangkan, suka membolos sekolah, tidak mendengarkan guru, menyontek dan sebagainya. Dalam hal ini berarti guru tidak berhasil dalam memberi motivasi yang tepat untuk mendorong agar peserta didik bekerja dengan segenap tenaga dan pikirannya. Banyak bakat anak yang tidak berkembang karena tidak diperoleh motivasi yang tepat, jika seorang mendapat motivasi yang tepat, maka paduan tenaga yang luar biasa sehingga tercapai hasil yang semula tidak terduga (Purwanto, 1990).

Motivasi juga bisa dikatakan rencana atau keinginan untuk menuju kesuksesan dan menghindari kegagalan hidup. Dengan kata lain, motivasi adalah sebuah proses untuk tercapai nya suatu tujuan (Majid, 2013).

Dalam upaya meningkatkan motivasi belajar, faktor-faktor yang mempengaruhi motivasi belajar siswa perlu mendapatkan perhatian serius. Permasalahannya adalah bagaimana membujuk siswa atau peserta didik untuk berusaha mengembangkan semangat belajarnya supaya mendapatkan motivasi yang optimal. Semangat bisa timbul dari dalam maupun dari luar individu, sehingga diperlukan suatu penelitian agar dapat memberikan solusi yang tepat bagaimana 
menumbuhkan semangat belajar yang dapat mendukung tercapainya motivasi belajar yang maksimal atau diinginkan, (Kompri, 2016).

Pemberian reward kepada suatu objek (siswa) tentunya bukan tanpa maksud tertentu, reward diberikan pada seseorang dengan dalih agar orang tersebut mau belajar dengan baik, lebih giat, lebih rajin dan lebih bertanggung jawab dengan tugas yang diemban. Memang agak terkesan memaksa, dimana ada anggapan bahwa kita hanya mau melakukan sebuah pekerjaan hanya karena mengejar reward, dengan kata lain kita tak bekerja dengan ikhlas. Akan tetapi dalam suatu proses belajar mengajar, reward diberikan sebagai salah satu bentuk motivator bagi siswa untuk meraih hasil sebaik mungkin. siswa berhak mendapat hadiah atau pujian setelah melakukan suatu perbuatan yang baik, hadiah dipandang lebih efektif sebagai penguat perilaku karena hasilnya nyata atau jelas Sagala (2012), dan ketika sudah menjadi satu kebiasaan baik maka intensitas reward sedikit demi sedikit mulai dikurangi.

Pemberian perhatian yang cukup terhadap siswa dengan segala potensi yang dimilikinya merupakan bentuk motivasi yang sederhana, karena banyak yang tidak memiliki motivasi belajar diakibatkan tidak dirasakannya adanya perhatian. Sebagaimana yang dijelaskan Dimyati dan Mudjiono (2002) prinsip-prinsip yang berkaitan dengan perhatian dan motivasi pembelajaran yaitu perhatian merupakan peranan penting dalam kegiatan belajar.

Dalam Al-Qur'an banyak membahas tentang penerapan reward dalam rangka memotivasi umat manusia untuk beramal sholeh dan mencegahnya dari perbuatan jahat dan buruk. Salah satu ayat yang berkenaan dengan pemberian reward.

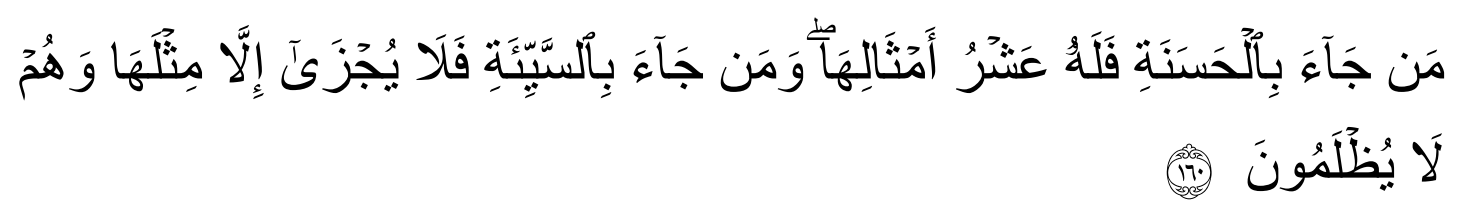

Artinya: barangsiapa membawa amal yang baik, maka baginya (pahala) sepuluh kali lipat amalnya; dan barangsiapa yang membawa perbuatan jahat maka dia tidak diberi pembalasan melainkan seimbang dengan kejahatannya, sedang mereka sedikitpun tidak dianiaya (dirugikan). (QS. Al An'am :160)

Dalam mengatasi beberapa persoalan tersebut dibutuhkan sebuah strategi atau metode untuk melatih siswa agar mau berbicara atau aktif selama proses pembelajaran. Salah satu metode pembelajaran yang dapat diterapkan yaitu metode pemberian reward, reward di sini sama dengan ganjaran. Reward (ganjaran) adalah hadiah atau penghargaan terhadap perilaku baik dari anak didik dalam proses 
pendidikan, Fatturahman (2012). Penghargaan yang diberikan sangat beragam dan tidak selalu dalam bentuk uang, tetapi bisa dalam bentuk pujian, barang, nilai (sekolah) dan lain sebagainya.

Tidak jauh berbeda dalam dunia pendidikan, guru seharusnya menerapkan metode pemberian reward kepada anak didiknya dalam kegiatan pembelajaran baik berupa materi maupun non materi sebagai alat memotivasi siswa agar peserta didik mempunyai semangat yang tinggi dalam belajarnya. Dalam penelitian ini mencoba membuat siswa lebih aktif didalam kegiatan pembelajaran, dan meningkatkan semangat belajar dalam diri siswa. Dengan pemberian reward kepada siswa, diharapkan dapat meningkatkan motivasi mereka untuk lebih giat belajar dalam proses pembelajaran di kelas.

\section{METODE PENELITIAN}

Metode yang digunakan dalam penelitian ini adalah metode survai (survey). Sukmadinata (2013) menjelaskan bahwa metode survai merupakan metode penelitian yang digunakan untuk mengumpulkan informasi berbentuk opini dari sejumlah besar orang terhadap topik atau isu-isu tertentu. Dalam prosesnya, penulis menggunakan metode dan pendekatan kuantitatif korelatif, yaitu untuk mengetahui pengaruh pemberian reward dalam pendidikan Agama Islam terhadap motivasi belajar siswa pondok kelapa, Jakarta Timur. Penelitian ini bertujuan untuk mencari ada tidaknya pengaruh variable independen terhadap variable dependen. Populasi yang diteliti dalam penelitian ini adalah seluruh siswa kelas VIII di SMPIT Ar-Rudho pondok kelapa, Jakarta Timur yang berjumlah 60 siswa, Adapun waktu penelitian dilaksanakan selama 3 bulan terhitung dari bulan Oktober s/d Desember 2018, mulai dari perencana sampai dengan pembuatan laporan penelitian.

Sampling jenuh/total adalah teknik penutupan sampel bila semua anggota populasi digunakan sebagai sampel (Azwar, 2017). Hal ini sering dilakukan bila jumlah populasi relatif kecil, kurang dari 30 orang, atau penelitian yang ingin membuat generalisasi dengan kesalahan yang sangat kecil. Istilah lain sampel total adalah sensus, dimana semua anggota populasi dijadikan sampel, Sehingga populasi nya 60 orang dan sampelnya juga 60 orang.

Tabel 1

Daftar Siswa Kelas

\begin{tabular}{ccrr}
\hline No & Kelas & Populasi & \multicolumn{1}{c}{ Sampel } \\
\hline 1 & VIII A & 20 & 20 \\
\hline 2 & VIII B & 20 & 20 \\
\hline 3 & VIII C & 20 & 20 \\
\hline & Jumlah & $\mathbf{6 0}$ & $\mathbf{6 0}$ \\
\hline
\end{tabular}


Tabel 2

Kisi - kisi Angket Pemberian Reward

\begin{tabular}{|c|c|c|c|c|}
\hline \multirow{2}{*}{ No } & \multirow{2}{*}{ Indikator } & \multicolumn{2}{|c|}{ Item } & \multirow{2}{*}{ Jumlah } \\
\hline & & $(+)$ & $(-)$ & \\
\hline \multirow[t]{2}{*}{1} & \multirow{2}{*}{$\begin{array}{l}\text { Guru memberikan kata - kata } \\
\text { yang baik berupa do'a dan } \\
\text { senyuman }\end{array}$} & $1,2,3$ & 4,5 & 5 \\
\hline & & & & \\
\hline 2 & Guru memberikan pujian & $\begin{array}{c}6,7,8,9,10,12,13 \\
16,17\end{array}$ & 11,14 & 11 \\
\hline 3 & $\begin{array}{l}\text { Guru memberikan nilai } \\
\text { tambahan }\end{array}$ & $15,18,21$ & $19,20,22$ & 6 \\
\hline \multirow[t]{2}{*}{4} & $\begin{array}{l}\text { Pemberian hadiah semangat } \\
\text { dalam belajar }\end{array}$ & $\begin{array}{c}23,24,25,26,27,2 \\
8\end{array}$ & 29,30 & 8 \\
\hline & Jumlah & 21 & 9 & 30 \\
\hline
\end{tabular}

Tabel 3

Kisi-kisi Angket Motivasi Belajar

\begin{tabular}{|c|c|c|c|c|}
\hline \multirow{2}{*}{ No } & \multirow{2}{*}{ Indikator } & \multicolumn{2}{|c|}{ Item } & \multirow{2}{*}{ Jumlah } \\
\hline & & $(+)$ & $(-)$ & \\
\hline 1 & Tekun menghadapi tugas & $1,2,3$ & $4,5,6$ & 6 \\
\hline 2 & $\begin{array}{l}\text { Ulet menghadapi kesulitan (tidak } \\
\text { putus asa) }\end{array}$ & $7,8,9$ & $10,11,12$ & 6 \\
\hline 3 & Menunjukan semangat dalam belajar & $13,14,15,18$ & 16,17 & 6 \\
\hline 4 & Lebih senang bekerja mandiri & $19,20,21$ & $22,23,24$ & 6 \\
\hline 5 & $\begin{array}{l}\text { Cepat bosan pada tugas-tugas yang } \\
\text { rutin }\end{array}$ & 25 & 26 & 2 \\
\hline \multirow[t]{2}{*}{6} & $\begin{array}{l}\text { Dapat mempertahankan } \\
\text { pendapatannya }\end{array}$ & $27,28,29$ & 30 & 4 \\
\hline & Jumlah & 17 & 13 & 30 \\
\hline
\end{tabular}

Selanjutnya melakukan anlisis Korelasi hasil pengolahan data penelitian diperoleh nilai koefisien korelasi menggunakan rumus sebagai berikut:

$$
r_{x y}=\frac{n \sum X Y-\sum X \sum Y}{\sqrt{\left\{n \sum X^{2}-\left(\sum X\right)^{2}\right)\left\{n \sum Y^{2}-\left(\sum Y\right)^{2}\right\}}}
$$

Setelah penelitian melakukan teknik pengumpulan data melalui skala, tes, observasi dan wawancara, data yang berhasil dikumpulan oleh penulis kemudian diolah. Kemudian untuk mengetahui koefisien korelasi antara dua variabel yang 
digunakan dalam penelitian ini penulis memasukkan hasil penjumlahan skor kedalam rumus " $\mathrm{r}$ " product moment.

\section{HASIL DAN PEMBAHASAN}

Deskripsi data pada bagian ini meliputi data variabel X (Pemberian Reward) sebagai variabel independen dan variabel Y (Motivasi Belajar) sebagai variabel terikat/dependen. Data pemberian Reward mempunyai kemungkinan skor tertinggi sebesar 110 dari 22 pernyataan yang valid dalam angket. Kemudian data yang diperoleh di lapangan diolah secara statistik ke dalam daftar distribusi frekuensi, banyaknya kelas dihitung menurut aturan Sturges, diperoleh enam kelas dengan nilai skor maksimum 93 dan skor minimum 44, sehingga rentang skor sebesar 49. Berdasarkan hasil perhitungan statistik deskriptif diperoleh bahwa variabel Model Pemberian Reward mempunyai nilai rata-rata (mean) sebesar 68,57 dengan nilai standar deviasi 11,28 dan nilai variansnya sebesar 127,23, nilai median 69 dan nilai modus sebesar 65. Pengelompokkan data dapat terlihat pada tabel distribusi frekuensi sebagai berikut:

Tabel 4

Distribusi Frekuensi Variabel Pemberian Reward

\begin{tabular}{ccc}
\hline Skor Pemberian Reward & Frekuensi & \% \\
\hline $44-51$ & 6 & 10 \\
\hline $52-59$ & 6 & 10 \\
\hline $60-67$ & 15 & 25 \\
\hline $68-75$ & 18 & 30 \\
\hline $76-84$ & 10 & 16.66 \\
\hline $85-92$ & 5 & 8.33 \\
\hline Jumlah & 60 & 100 \\
\hline
\end{tabular}

Secara visual grafik batang dari distribusi data skor Pemberian Reward tersebut seperti tertera dalam gambar berikut:

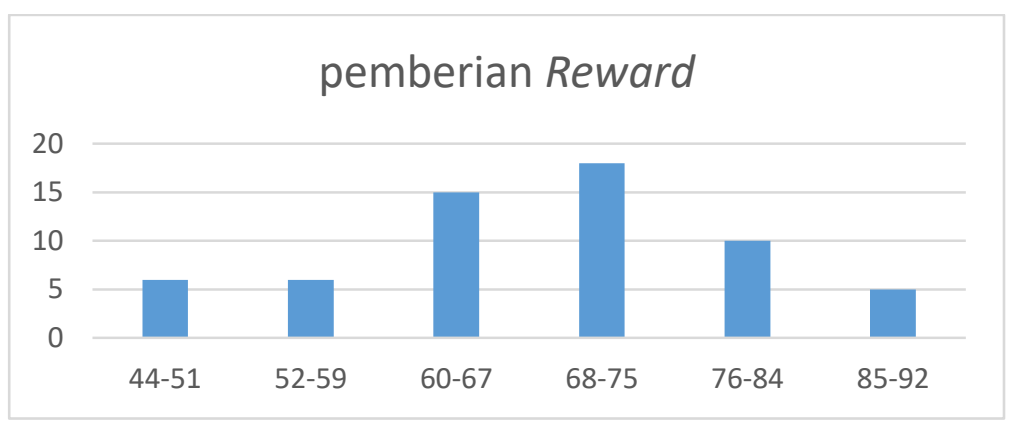

Gambar 1. Grafik Distribusi Skor Pemberian Reward 
Berdasarkan table di atas diperoleh nilai rata-rata hitung (mean) sebesar 68,57, nilai ini setara dengan 62,33\% (68,57/110 x 100\%) dari kemungkinan skor tertinggi. Dengan demikian penggunaan Pemberian Reward di kelas VIII SMP IT ArRudho yang terletak di Pondok Kelapa, Kota Jakarta Timur, termasuk dalam kategori baik.

\section{Motivasi Belajar pada mata pelajaran PAI}

Data motivasi belajar mempunyai kemungkinan skor tertinggi sebesar 125 dari 25 pernyataan yang valid dalam angket. Kemudian data yang diperoleh di lapangan diolah secara statistik ke dalam daftar distribusi frekuensi, banyaknya kelas dihitung menurut aturan Sturges, diperoleh enam kelas dengan nilai skor maksimum 110 dan skor minimum 45, sehingga rentang skor sebesar 65. Berdasarkan hasil perhitungan statistik deskriptif diperoleh bahwa variabel Motivasi Belajar mempunyai nilai rata-rata (mean) sebesar 73,45 dengan nilai standar deviasi 13,70 dan nilai variansnya sebesar 187,77 nilai median 72 dan nilai modus sebesar 71 . Pengelompokkan data dapat terlihat pada tabel distribusi frekuensi sebagai berikut:

Tabel 5

Distribusi Frekuensi Variabel Motivasi Belajar

\begin{tabular}{ccc}
\hline Skor Motivasi Belajar & Frekuensi & $\boldsymbol{\%}$ \\
\hline $45-55$ & 5 & 8.33 \\
\hline $56-66$ & 17 & 28.33 \\
\hline $67-77$ & 14 & 23.33 \\
\hline $78-88$ & 14 & 23.33 \\
\hline $89-99$ & 9 & 15 \\
\hline $100-110$ & 1 & 1.66 \\
\hline Jumlah & 60 & 100 \\
\hline
\end{tabular}

Secara visual grafik batang dari distribusi data variabel Motivasi Belajar pada matapelajaran PAI tersebut seperti tertera dalam gambar berikut:

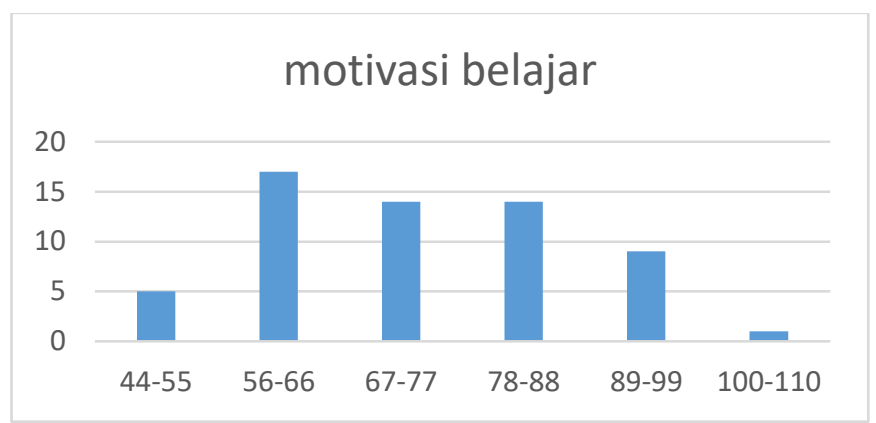

Gambar 2. Grafik Distribusi Skor Motivasi Belajar 
Berdasarkan table di atas diperoleh nilai rata-rata hitung (mean) sebesar 73,45 nilai ini setara dengan 63,86\% (73,45/115 x 100\%) dari kemungkinan skor tertinggi. Dengan demikian Motivasi Belajar kelas VIII SMP IT Ar-Rudho yang terletak di pondok kelapa, Kota Jakarta Timur, termasuk dalam kategori baik.

\section{Uji Signifikansi dan Linieritas Regresi}

Pengujian hipotesis penelitian dilaksanakan dengan menggunakan teknik analisis regresi dan korelasi. Analisis regresi digunakan untuk memprediksi model hubungan sedangkan analisis korelasi digunakan untuk mengetahui kadar pengaruh antar variabel penelitian.Pada tahap permulaan pengujian hipotesis adalah menyatakan pengaruh antara variabel bebas dengan variabel terikat dalam bentuk persamaan regresi sederhana. Persamaan tersebut ditetapkan dengan menggunakan data hasil pengukuran yang berupa pasangan variabel bebas dengan variabel terikat sedemikian rupa sehingga model persamaan regresi merupakan bentuk hubungan yang paling cocok.

Pada tahap selanjutnya adalah melakukan analisis korelasional dengan meninjau kadar dan signifikansi hubungan antara pasangan variabel bebas dengan variabel terikat. Kadar hubungan diuji dengan menggunakan nilai koefisien korelasi "Product Moment Pearson ( $r)$ " dan nilai koefisien determinasi $\left(\mathrm{r}^{2}\right)$. Tingginya nilai dari kedua koefisien tersebut menunjukkan tingginya pengaruh atau korelasi antara variabel yang dianalisis.Uji linieritas koefisien regresi motivasi belajar siswa atas pemberian Reward adalah sebagai berikut:

\section{Tabel 6}

Analisis Variansi untuk Uji Linieritas Koefisien Regresi

\begin{tabular}{|c|c|c|c|c|c|c|}
\hline & & & $\begin{array}{l}\text { Sum of } \\
\text { Squares }\end{array}$ & Df & Mean Square & $\mathrm{F}$ \\
\hline \multirow[t]{5}{*}{$Y$ atas $\mathrm{X}$} & $\begin{array}{l}\text { Between } \\
\text { Groups }\end{array}$ & (Combined) & 5973.900 & 30 & 199.130 & 1.336 \\
\hline & & Linearity & 1658.145 & 1 & 1658.145 & 11.129 \\
\hline & & $\begin{array}{l}\text { Deviation from } \\
\text { Linearity }\end{array}$ & 4315.755 & 29 & 148.819 & 999 \\
\hline & Within $\mathrm{G}_{1}$ & ups & 4320.833 & 29 & 148.994 & \\
\hline & Total & & 10294.733 & 59 & & \\
\hline
\end{tabular}

Berdasarkan table di atas pada Linearity diperoleh nilai $\mathrm{F}$ hitung sebesar 26.229, nilai ini lebih besar dari $\mathrm{F}$ tabel $(\alpha=5 \%, \mathrm{db} 1=1, \mathrm{db} 2=29)=4.18$ maka tolak $\mathrm{H}_{0}$. Sehingga dapat disimpulkan bahwa persamaan Pengaruh Pemberian Reward Terhadap Motivasi Belajar Siswa pada Mata Pelajaran PAI berbentuk linear. 


\section{Analisis Korelasi}

Analisis korelasi bertujuan untuk mengukur keeratan asosiasi (hubungan) linear antara dua variabel. Korelasi juga tidak menunjukkan hubungan fungsional. Dengan kata lain, analisis korelasi tidak membedakan antara variabel dependen dengan variabel independen. Berdasarkan hasil pengolahan data penelitian diperoleh nilai koefisien korelasi sebagai berikut:

$$
\begin{aligned}
r_{x y} & =\frac{n \sum X Y-\sum X \sum Y}{\sqrt{\left\{n \sum X^{2}-\left(\sum X\right)^{2}\right)\left\{n \sum Y^{2}-\left(\sum Y\right)^{2}\right\}}} \\
& =\frac{60(304810)-(4114)(4394)}{\sqrt{\left\{60(289590)-(4114)^{2}\right\}\left\{60(332082)-(4394)^{2}\right\}}} \\
& =0,401
\end{aligned}
$$

Dari tabel di atas terlihat bahwa koefisien korelasi antara Pemberian Reward dengan Motivasi Belajar dengan siswa pada mata pelajaran PAI sebesar 0,401 . Nilai $r_{x y}=0,401$ lebih besar $r$ tabel product moment $\left(r_{5} \%(58)=0,254\right)$ sehingga dapat dinyatakan bahwa korelasi antara antara Pemberian Reward dengan Motivasi Belajar dengan siswa pada mata pelajaran PAI (X) dengan minat belajar siswa pada mata pelajaran PAI (Y) sangat signifikan.Nilai koefisien korelasi antara antara Pemberian Reward dengan Motivasi Belajar dengan siswa pada mata pelajaran PAI sebesar 0,401, menandakan bahwa terdapat korelasi yang cukup kuat diantara keduanya.

\section{SIMPULAN}

Pemberian metode reward sudah diterapkan di sekolah SMP IT Ar-Rudho Jakarta Timur kususnya untuk semua kelas dari kelas VII, VIII dan IX. Adapun reward yang diberikan sangat beragam tidak selalu berbentuk uang, tetapi bisa dalam bentuk pujian, barang, nilai (sekolah) bagi siswa yang bisa menjawab pertanyaan guru atau pada saat ulangan harian dan lain sebagainya. Metode tersebut dapat memacu siswa lebih giat dalam proses pembelajaran di sekolah. Motivasi belajar siswa di SMP IT Ar-Rudho Jakarta. Dengan adanya pemberian reward dapat meningkatkan motivasi belajar siswa, karena dengan metode pemberian reward akan menciptakan suasana belajar yang menyenangkan supaya metode mengajar yang digunakan guru tidak terlalu monoton seperti metode ceramah yang sering digunakan guru dalam belajarnya dan diharapkan dapat menertibkan siswa yang mengganggu proses belajar mengajar dan dapat mencegah berbagai pelanggaran terhadap peraturan. Berdasarkan interprestasi data yang dapat dikemukakan yaitu terdapat pengaruh pemberian reward terhadap motivasi belajar siswa. Dari kelas VII yang di 
jadikan sampel penelitian terdapat pengaruh dari pemberian reward terhadap motivasi belajar siswa. Dikarenakan yaitu kesenangan mereka dengan metode reward karena membuat suasana pembelajaran tidak membosankan dari hasil penelitian yang dilakukan, Hal ini dapat dilihat dari beberapa hasil pengujian yang telah dilakukan peneliti berupa penyebaran angket yaitu pada uji koefisien korelasi yang mana nilai

$\mathrm{r}_{\text {hitung }}$ sebesar 0,401 lebih besar dari $\mathrm{r}_{\text {tabel }}$ product moment $=0,254$ pada taraf signifikansi $5 \%$ dan $n=60$. Sehingga hipotesis nihil $\left(\mathrm{H}_{\mathrm{o}}\right)$ ditolak dan hipotesis alternatif $\left(\mathrm{H}_{1}\right)$ diterima.

\section{DAFTAR PUSTAKA}

Majid, A. (2013). Strategi Pembelajaran. Bandung : PT Remaja Rosdakarya Azwar, S. (2017). Metode Penelitian, Yogyakarta : Pustaka Pelajar.

Dimyati \& Mudjiono. ( 2002). Belajar dan Pembelajaran, Jakarta : Rineka Cipta

Fatturahman. M. (2012). Belajar Pembelajaran Meningkatkan Mutu Pembelajaran

Sesuai Standar Nasional, Yogyakarta : Teras

Kompri. (2016). Motivasi pembelajaran Perspektif Guru dan Siswa. Bandung : Remaja Rosdakarya.

Purwanto, N. (1990). Belajar Berhubungan Dengan Perubahan Tingkah Laku,

Jakarta : PT Rineka Cipta

Rohmad, W. (2009). Mahami Pendidikan dan Ilmu Pendidikan, Yogyakarta : Laskbang Mediatama

Sukmadinata \& Nana, S. (2013). Metode Penelitian Pendidikan, Bandung : PT. Remaja Rodakarya

Syaiful, S. (2012). Konsep dan Makna Pembelajaran, Bandung : Alfabeta 